\title{
Evallndigenous Origin Story: Effective Practices within Local Contexts to Inform the Field and Practice of Evaluation
}

\author{
Larry Bremner \\ Proactive Information Services Inc. \\ Nicole Bowman \\ University of Wisconsin
}

\begin{abstract}
EvalIndigenous began in November 2015 as a global network of EvalPartners. This origin story of EvalIndigenous is shared to describe some of the work being carried out today by Indigenous evaluators in the Global North and South. EvalIndigenous is rooted in tribal critical and Indigenous theories and methods, as well as the legal and political distinctions of Indigenous peoples and Tribal/First Nations. EvalIndigenous shares how evaluation is done "by us and for us." The article concludes by highlighting key strategies that the field of evaluation can consider in the future when working with Indigenous populations and sovereign Tribal/First Nations governments and communities.
\end{abstract}

Keywords: EvalIndigenous, EvalPartners, evaluation, governance, government evaluation, Indigenous evaluation, Indigenous theory, systems evaluation, tribal critical theory, Tribal/First Nation, truth and reconciliation, United Nations

Résumé : EvalIndigenous a été lancé en novembre 2015 comme réseau mondial d'EvalPartners. La genèse d'EvalIndigenous décrit certains aspects du travail effectué par des évaluateurs et évaluatrices autochtones du Nord et du Sud à l'échelle de la planète. EvalIndigenous est fondé sur les méthodes et les théories autochtones et tribales critiques, de même que sur les particularités juridiques et politiques des peuples autochtones et des tribus/Premières nations. EvalIndigenous s'intéresse à l'évaluation "par nous et pour nous ». L'article souligne en conclusion les principales stratégies dont le domaine de l'évaluation devrait se préoccuper lorsqu'il s'agit de travailler avec des populations autochtones et des communautés et gouvernements souverains tribaux/ Premières nations.

Mots clé : EvalIndigenous, EvalPartners, évaluation, gouvernance, évaluation gouvernementale, évaluation autochtone, théorie autochtone, évaluations des systèmes, théorie tribale critique, tribu/Première Nation, vérité et réconciliation, Nations Unies

Corresponding Author: Nicky Bowman, Bowman Performance Consulting, W7023

Edgewater Road, Shawano, WI, 54166 USA; nicky@bpcwi.com

(C) 2020 Canadian Journal of Program Evaluation / La Revue canadienne d'évaluation de programme 34.3 (Special Issue / Numéro spécial), 425-441 doi: 10.3138/cjpe.68914 


\section{EVALINDIGENOUS: THE ORIGIN STORY}

The International Organization for Cooperation in Evaluation (IOCE) represents international, national, sub-national, and regional Voluntary Organizations for Professional Evaluation (VOPEs) worldwide. EvalPartners was launched in March 2012 by the IOCE and the United Nations, in partnership with several other international development organizations. The past-president of the Canadian Evaluation Society (CES) serves as treasurer to the IOCE and is a member of the EvalPartners Management Group (EPMG). As a global partnership, EvalPartners supports Civil Society Organizations (CSO) and VOPEs in their use and practice of evaluation at the regional, national, and international levels. This support is intended to increase the likelihood that public policies will be informed by evidence and that considerations of equity and effectiveness will be incorporated into public policy decision making. The work of EvalPartners takes many directions, one of which has been the formation of global networks, each of which has a specific focus. The networks are EvalGender+, EvalYouth, EvalSDGs (Sustainable Development Goals), the Global Parliamentarian Forum, and the newest network, EvalIndigenous.1

The origin story of EvalIndigenous is shared to describe some of the work being carried out by Indigenous evaluators in the Global North and South. EvalIndigenous is rooted in tribal critical and Indigenous theories and methods, as well as the legal and political distinctions of Indigenous peoples and Tribal/First Nations. EvalIndigenous shares how evaluation is done "by us and for us." The article concludes with highlighting key strategies that the field of evaluation can consider when working with Indigenous populations and sovereign Tribal/First Nations governments and communities.

The desire for a global Indigenous network resulted from the reality that Indigenous peoples are often directly affected by evaluation results, which inform decisions regarding merit, worth, and value. However, many evaluators do not take into consideration the cultural context, complexities, or histories of the communities in which they are working. As noted by Kirkhart, LaFrance, and Nichols (2011, p. 3),

Merit and worth are the culmination of a lifelong journey towards self-actualization that is realized within the shared meanings and cultural parameters of community. Historical trauma must be addressed, and evaluation must contribute to learning that supports cultural renewal and revitalization. Self-determination must be understood by the evaluators as a necessary condition of good evaluation.

In February 2015, during an EPMG meeting, the CES past-president raised the need for an Indigenous global network. It was argued that many evaluators working in Indigenous communities were unaware of Indigenous evaluation approaches and enter communities as transients, unfamiliar with community protocols and contexts. The Indigenous network was initially conceptualized by the EvalPartners Management Group as EvalCulture. The intent was to bring together individuals 
and organizations across the various organizations and communities. This network would identify and share best practices and lessons learned when undertaking evaluation with marginalized peoples, oppressed populations, and Indigenous communities. Considering the scope of EvalGender+, which is focused on equity- and gender-responsive evaluation, it was decided that issues related to many of the marginalized populations originally included in EvalCulture could be addressed by EvalGender+. Therefore, the focus and name of EvalCulture was revised in August 2015 to become EvalIndigenous; this name change more clearly stated the intent of the network. For First Peoples who have been colonized, and in many cases experienced cultural genocide, it was argued that too often they are incorporated into broad categories where their unique histories and contexts are not accurately captured and recognized. Therefore, EvalIndigenous was launched as a global network in November 2015 in the Parliament of Nepal. As noted in the revised EvalIndigenous concept paper (Bremner \& Were, 2016), EvalIndigenous was intended to involve Indigenous peoples in leading and contributing to global evaluation practice and endeavours. Furthermore, EvalIndigenous was intended to increase the awareness of individuals engaged in evaluation with Indigenous communities by documenting the evaluation protocols developed by Indigenous communities and organizations, facilitating learning and sharing of experiences, promoting innovation in approaches and methods used in Indigenous evaluation, and disseminating information regarding lessons learned. Finally, EvalIndigenous facilitates the creation of spaces that promote Indigenous peoples' self-determination of their evaluation agenda, cultivating an understanding and use of different evaluation approaches and methods to ensure that evaluators and evaluations are culturally responsive and inclusive.

EvalIndigenous is a multi-stakeholder partnership that includes representatives from VOPEs such as the American Evaluation Association (AEA), African Evaluation Association (AfrEA), African Gender and Development Evaluators Network (AGDEN), Asia Pacific Evaluation Association (APEA), Australian Evaluation Association (AES), Canadian Evaluation Society (CES), Cameroon Development Evaluation Association (CaDEA), Māori Evaluation Association (Ma te Rae), Latin American Evaluation Association (ReLAC), Red Nicaraguense de Seguimiento y Evaluation (ReNicSE), and Zambia Measurement and Evaluation Association (ZaMEA). Currently, EvalIndigenous receives funding through the IOCE from the Swiss Agency for Development and Cooperation. Membership has been growing as awareness of EvalIndigenous increases. Membership is open to both Indigenous individuals and non-Indigenous allies and, to date, EvalIndigenous has approximately 80 members around the world.

Through the recognition of different Indigenous worldviews and valuing the strengths of Indigenous evaluation practices, EvalIndigenous sets out to advance the contribution of Indigenous evaluation to global evaluation practice. As noted in an EvalIndigenous Pop-Up-Note (PUN):

EvalIndigenous seeks to bring awareness to, include, and celebrate the cultural traditions and values, languages, legal/political governance practices, and ways of life of 
Indigenous peoples wherever they live. Our focus is to ensure that policies and evaluation practices for Indigenous peoples are based on equity, fairness and justice. The United Nations Declaration on the Rights of Indigenous Peoples (United Nations, 2008) frames our work, moving from an evidence-based focus towards a shared global understanding of good practice for Indigenous peoples and our rights within the field of evaluation. (EvalIndigenous, 2019a)

When discussing Indigenous peoples, EvalIndigenous aligns with the United Nations Permanent Forum on Indigenous Issues, which states:

The most fruitful approach is to identify, rather than define Indigenous peoples. This is based on the fundamental criterion of self-identification as underlined in several human rights documents .... In some countries, there may be preference for other terms including tribes, first peoples/nations, Aboriginals, ethnic groups, adivasi, janajati. (United Nations Permanent Forum on Indigenous Issues, n.d. a, p. 1)

In 2017, EvalIndigenous sent a link to a web-based survey to the global VOPEs to better understand VOPEs' engagement with Indigenous evaluators (IE) and Indigenous communities (IC) in their countries and regions. Additionally, it was expected that survey results would support VOPEs in developing awareness and support for Indigenous evaluation, Indigenous evaluators, and Indigenous communities. This survey revealed several challenges and the opportunities they present.

It was found that most VOPEs do not collect ethnicity-related information about their members. This presents a challenge when considering the Briefing Note: Indigenous Peoples' Rights and the 2030 Agenda: Sustainable Development Goals, from the United Nations (2017, p. 3), which states,

Data-disaggregation according to Indigenous or ethnic identity across all sustainable development goals must also be included to monitor progress for Indigenous peoples. A critical priority at national level is, therefore, to ensure that data disaggregation includes "Indigenous identifiers" (for instance language or self-identification) in official statistics to capture the inequalities Indigenous peoples face across all the sustainable development goals.

In fact, some VOPEs did not believe Indigenous peoples were in their countries. Thus, preferred treatment of Indigenous peoples was unnecessary, in their context, because most of the population was Indigenous. As noted by one VOPE, "We are not sure that the Indigenous agenda applies to our country as it would apply to other countries, like US, Canada, Colombia, Argentina, etc. Not sure of how relevant it is to us and it definitely feels that it is more relevant to (advanced) countries" (Goodwin \& Bremner, 2018).

Further, while approximately half of the 27 VOPEs work with Indigenous communities, few had guidelines for how to work with them. This could provide other challenges as there is a need to understand that Indigenous evaluation approaches are "inherently rooted in community and cannot be conceived of otherwise" (Easby, 2016, p. 1). EvalIndigenous is attempting to address these 
challenges by increasing VOPEs' and evaluators' understanding through vehicles such as presentations at conferences, webinars, and brief publications. Examples are available at the EvalIndigenous Google drive shared space, are regularly posted on the EvalIndigenous Facebook group, and are available upon written request by e-mailing EvalIndigenous members.

EvalIndigenous advocates for evaluation approaches that support the improvement of community well-being in terms of physical, mental, emotional, and spiritual development of individuals and families. According to Chilisa (2012), postcolonial Indigenous theory "gives researchers [evaluators] the tools to theorize Indigenous research [evaluation], Indigenous research [evaluation] paradigms, and culturally integrative research [evaluation] approaches" (p. 50). There is a need to understand that Indigenous evaluation has at its core enrichment, development, learning, celebration, and reconciliation (Alfred, 2009; Bowman, Dodge-Francis, \& Tyndall, 2015; Chilisa, 2012; Easby, 2016; Kirkhart et al., 2011; LaFrance \& Nichols, 2010; Rowe \& Kirkpatrick, 2018; Smith, 1999; Wilson, 2008). Almost a quarter-century ago, Rigney suggested that "Indigenous people are at a stage where they want research [evaluation] and research [evaluation] design to contribute to their self-determination and liberation struggles, as it is defined by their communities" (as cited in Wilson, 2008, p. 54). This call has been renewed by Cram, Tibbetts, and LaFrance (2018, p. 11), who state: "the time is now for Indigenous Evaluation (IE) . . . the time is right for asserting Indigenous paradigms, methodologies, and methods for evaluation, evaluation capacity building, and research on evaluation." It is the intent of EvalIndigenous to advance these Indigenous paradigms and processes.

\section{EVALINDIGENOUS: OUR ROOTS}

There are multiple Indigenous, critical, and decolonization theories that inform the work of EvalIndigenous (Bowman, 2018; Bowman et al., 2015; Chandna et al., 2019; Chilisa, 2012; Kovach, 2010; LaFrance \& Nichols, 2010; Mertens, Cram, \& Chilisa, 2013; Smith, 2012; Wehipeihana, Bailey, Davidson, \& McKegg, 2014). EvalIndigenous is firmly rooted in community-centred and culturally responsive Indigenous foundations that apply to the communities and nations in the Indigenous Global North and South. Indigenous theories and practices being done "for us and by us" are the community bedrock upon which EvalIndigenous was founded. Tribal Critical Theory (TCT) (Brayboy, 2005) provides a living Indigenous framework that is seen in much of the work of EvalIndigenous. Succinctly, the TCT tenets are as follows:

1. Colonization is endemic to society.

2. U.S. or other nation/state policies toward Indigenous people are rooted in imperialism, White supremacy, and desire for material gain.

3. Indigenous identity is both political and cultural.

4. Indigenous people have rights to tribal sovereignty, autonomy, selfdetermination, and self-identification. 
5. Culture, knowledge, and power have different meanings through Indigenous lenses.

6. Government and education or other policies for Indigenous people are linked to the problematic goal of assimilation.

7. Cultural traditions and philosophies are central to the lived realities, differences, and adaptability of Indigenous people.

8. Theories and stories are not separate but are legitimate sources of data and ways of being.

9. Theory and practice are connected in deep and explicit ways, so scholars must work toward social change.

EvalIndigenous recognizes continual impacts of colonization (past and present) and intentionally privileges Indigenous traditional ecological knowledge, cultural, and traditional protocols. Also, the linguistic and clan or family practices help to carry out and sustain meaningful evaluation within local contexts. Beyond the cultural, traditional, and community-centred foundations, EvalIndigenous also recognizes and incorporates the legal, political, and human rights components of conducting effective evaluations with Tribal/First Nations and Indigenous populations (Barker, 2005; Bowman \& Dodge-Francis, 2018; EchoHawk, 2013).

Not all Indigenous populations globally have Tribal or First Nations governments. However, all Indigenous populations have unique human rights as outlined in article 43 of the United Nations Declaration on the Rights of Indigenous Peoples (UNDRIP) (United Nations, 2008). Therefore, more recent scholars have called for "nation to nation" evaluations (Bowman, 2019; Shepherd \& McCurry, 2018) that call for a co-production framework as part of a broader global call to action for protection of treaty rights (Reinhardt, 2008) and data sovereignty (Kukutai \& Taylor, 2016), where Tribal Nations create resolutions and ordinances for protections in research, policy, evaluation, and government studies (National Congress of American Indians, 2006-2019).

Building on TCT, nation-to-nation evaluations can be applied to systems, processes, and governance arrangements. They theorize how to conduct the work of EvalIndigenous when working with sustainable development goals (SDG), EvalSDG and EvalPartners' global efforts, and/or other evaluation parliamentarians and related VOPE initiatives (e.g., Blue Marble Group, CES's Diversity Working Group, AEA's Evaluation Policy Task Force). Working in a "nation-to-nation" orientation should be a professional, inclusive, and ethical effort for all VOPEs and/or global EvalPartners initiatives. One way of approaching this relationship is through Tribal Critical Systems Theory (TCST), which is described below (Bowman, in press). This theory may present an opportunity for non-Tribal partners to reflect and reconsider how they design and implement their future evaluation work:

1. The political power of public governments (i.e., nation/states) was achieved and is sustained through illegal, unjust, and unethical means. 
2. Public government (i.e., nation/state) constitutions and policies are founded on Christianity and the Doctrine of Discovery. Neither considered Indigenous people as humans. Currently, both ideologies continue to manifest through directly related federal, international, and case law.

3. Tribal/First Nations governments and people are the only racial/ethnic group that has inherent political and legal rights equal to U.S. federal and international governments through treaties and constitutional law.

4. By United Nations (UN) Resolution, the UNDRIP (United Nations, 2008) provides 46 articles that outline the global rights of Indigenous people and Tribal/First Nations, which most countries have formally adopted.

5. Culture, knowledge, and power are defined uniquely and locally through both traditional Indigenous governments and contemporary Tribal/First Nations constitutions, ordinances, policies, and community practices.

6. Tribal/First Nation government and educational policies are strengthsbased rather than critical or focus on deficits, and locally defined. Most importantly, these policies carry equal (or more) influence in federal (or state and municipal) public policy decision making and non-Tribal federal (or state and municipal) government contexts.

7. Traditional, cultural, and community-based philosophies, knowledge, and practices are the foundation of contemporary Tribal/First Nations governments who are working with non-Tribal governments to create responsive, effective, and sustainable systems, institutional policy changes, and implementation strategies.

8. Traditional history and knowledge that are orally transferred are essential to the scholarly and culturally responsive development and implementation of more effective policies, programs, and models.

9. Evaluating, generating, and replicating more effective Tribal/non-Tribal governance models that theoretically and practically provide better supports, improvements, and outcomes for sustained positive changes in Tribal/First Nations and Indigenous communities is a professional and ethical responsibility for all government, nonprofit, and academic partners.

Traditional knowledge and culture embedded in a community context along with the unique legal and political rights of Indigenous people are the guiding foundations to the work that EvalIndigenous carries out daily. These principles are actively applied through two working groups, which are described next. The broader EvalIndigenous membership works to implement the 2020 Agenda and current strategic plan that considers epistemologies and methods in all of their work.

In 2016, EvalIndigenous work helped create a draft foundational document as part of the "Global Context for Evaluation" work group. The foundational document is updated regularly and includes ongoing discussions and annual updates culminating in the EvalIndigenous 2020 Action Plan. Currently, this document is being reviewed by the United Nations Educational, Scientific, and Cultural 
Organization (UNESCO) as a potential paper to be published for the 2019 International Year of Indigenous Languages initiative (UNESCO, n.d.).

Additionally, a second "Global Practitioner" working group was formed so that the voices from grassroots Indigenous communities could be heard. Facilitated by EvalIndigenous members, the Global Practitioner group interviews Indigenous evaluators and documents evaluations conducted in the field. This groundbreaking Indigenous Voices Project commenced in 2016 (EvalPartners, n.d.) and is ongoing in an effort to better understand community-led evaluation activities in the Global North and South. The perspectives of the local evaluators in community and cultural contexts are being documented and understood through the Indigenous Voices Project. This is a critical aspect missing in practitioner or academic conversations and publications. Information is used not only to celebrate the diversity of Indigenous evaluators and their varied ways to design and implement studies "by and for" Indigenous communities globally, but also to value and celebrate the community context, cultural protocols, and traditional knowledge as the foundation to all aspects of an evaluation. It connects the academic or global policy work that EvalIndigenous carries out with VOPEs and the Global Parliamentarian Forum. Furthermore, the information collected from the Indigenous Voices Project interviews will be used to educate funders about how and who they could potentially fund to conduct evaluations in Indigenous communities. This will likely take many forms, such as person-to-person conversations, information pamphlets, social media, and webinars.

In the next section, several examples of current EvalIndigenous activities will be shared, including more information about the Indigenous Voices Project. They are intended to highlight how valuing and utilizing evaluation in Indigenous contexts and epistemologies can improve the appropriateness of evaluation designs and methods.

\section{EVALINDIGENOUS: OUR PRACTICE IN COMMUNITY AND CULTURAL CONTEXTS}

\section{Indigenous Voices Project}

Gaudry (2011) describes evaluation as an "extractive" process in which individuals are viewed as being "participants" or "informants" and where knowledge is "extracted." Contrarily, EvalIndigenous wants to build on the foundation of the knowledge and expertise of Indigenous peoples around the world through the Indigenous Voices Project. This project provides stories that document and promote the use of different Indigenous evaluation approaches. To date, 27 interviews have been recorded. Eight countries are represented, including: Australia, the continental United States, Alaska, Hawaii, South Africa, Cameroon, New Zealand, Canada, Papua New Guinea, and China. The intent of this project is to showcase the voices of Indigenous evaluation practitioners in the field.

For example, one participant in the Indigenous Voices Project, a member of the Yanakuna people from Colombia, described how they as a people are "recovering 
their roots" which were lost due to slavery and colonization. The recovery process has included regaining their symbols, fighting for their autonomy/sovereignty, and "recovering and healing from the pain caused by colonization." When evaluating from a "Yanakuna cosmovision" perspective, it was explained that they use a system of chacana, which is the star of the south, as a model of life. The chacana has four quadrants that are divided into two: the world above and the world below. The world above is the spiritual world and the world below is the material world. It was explained that, in contrast to Western approaches to evaluation, the Yanakuna approach includes the values of unity, autonomy, and culture. Specifically, the respondent said,

It is not like western evaluation, which is before, during and after. Instead we are revising ourselves constantly in order to strengthen that unity and the autonomy.... When we think of something that can transform our existence that is why we evaluate, to reflect, to change our existence and to strengthen ourselves. We must look at ourselves in a comprehensive way; where do we want to lead our well-living existence in relation to the material well-being and the spiritual well-being ... so evaluation for us is not just a moment as it is conceived from a western perspective. (EvalIndigenous, 2019b)

A respondent who is Pastos (Pastos communities are located in Ecuador and Colombia) highlighted the importance of relationality, which is similar to the Yanakuna people:

The Pastos Indigenous cosmovision sees everything holistically . . . we talk about harmony and an equilibrium which should exist in our community and within our people. Dissonance and imbalance are to our Indigenous people an indicator, a bad symptom which tells us something is wrong. (EvalIndigenous, 2019c)

The importance of spirituality, harmony, culture, unity, and sovereignty and how they are related are highlighted in these two interviews. These voices and others involved in the Indigenous Voices Project will be used to increase awareness of Indigenous practice, processes, and protocols. Additionally, this project will inform and educate funders about the importance of Indigenous worldviews and Indigenous-led evaluation in Indigenous communities.

\section{Evallndigenous Global Evaluation Gathering (2019)}

In February 2019, the Indigenous Peoples' Conference on Evaluation took place in Rotorua, New Zealand. EvalIndigenous was a sponsor for the conference, and several members of EvalIndigenous attended this global evaluation gathering. Approximately 120 individuals attended, the majority being Indigenous. Participants came from Aotearoa (New Zealand), Australia, the continental United States, Hawaii, Alaska, Cameroon, Canada, Samoa, and within the Arctic Circle. There were over 100 tribes/Tribal Nations represented. There were four keynote speakers, 18 presenters, and four Elders (the Kahui Pakeke). The importance of traditional knowledge was stressed throughout the conference, and all of the conference presentations can be seen on the Mā te Rae Facebook page (Mā te Rae - Māori 
Evaluation Association, n.d.). Participants centred, re-awakened, and upheld their traditional knowledge. It was not only an act of celebrating the timeless wisdom of ancestors but also an intentional act of decolonization. As Indigenous evaluation grows, rooted in traditional teachings and cultural/linguistic practices, capacity is being built, as well as a practical legacy nurtured and sustained for the next seven generations.

\section{United Nations and Indigenous populations activities (2019)}

The United Nations Permanent Forum on Indigenous Issues (UNPFII) was established in 2000 and is headquartered in New York City (United Nations Permanent Forum on Indigenous Issues, n.d.b). The 18th session of the UNPFII was held in April 2019 (United Nations Permanent Forum on Indigenous Issues, 2019). Prior to the session, a group of Indigenous leaders and evaluators gathered to develop indicators of success for UNPFII environmental and community-led activities. Over 20 Indigenous members from nine different countries gathered. They shared models of success, discussed and developed ways to gather data to measure it, and continue to work toward developing a response to the sustainable development goals and programming being carried out by the UN nations/states globally. The gathering emphasized the requirement to include culturally responsive indicators) and to ensure the visibility and inclusion of Indigenous voices and First Nations governments in global activities regarding sustaining the planet and natural resources. EvalIndigenous asked three of its members to attend and participate in this meeting. Piloting of models, metrics, and a UNPFII Indicator Convening Report will be completed in 2019, through the leadership of Dr. Eleanor Sterling, Chief Research Scientist, Center for Biodiversity and Conservation, American Museum of Natural History in New York City (American Museum of Natural History, n.d.). These performance metrics, Indigenous evaluation strategies, and nation-to-nation advocacy efforts, for the inclusion of Tribal/First Nations, are an ongoing part of EvalIndigenous members' work in their national VOPE activities. They are also highlighted in the work of EvalIndigenous with global EvalPartner and EvalSDG activities, and as part of an intentional outreach strategy at annual conferences of national evaluation societies. Consistently, EvalIndigenous strives to present, publish, and call meetings with global leadership to ensure that Indigenous voices and Tribal/First Nations continue to be included in these field of evaluation and policy discussions.

A second major activity with the UN is the submission of an EvalIndigenous language paper. This is in response to UNESCO's 2019 International Year of Indigenous Languages (IYIL) (United Nations, n.d.). Political, cultural, and geographic diversity of the membership and work of EvalIndigenous underscored the necessity to be responsive to IYIL. The paper highlighted genuine community-centred and language-driven projects that weave together evaluation, traditional ecological knowledge, and effective practices of local Indigenous evaluators. The paper, EvalIndigenous Dreamweavers: Embedding Language, Culture, and Community in the Global North and South, was submitted in March 2019. It contains case studies 
that illustrate the work of EvalIndigenous and members using language, cultural protocols, and traditional knowledge for evaluation. If selected, the EvalIndigenous Dreamweaver paper will be published and shared as part of UNESCO's 2019 IYIL. The purposes of submitting this paper are to

1. provide an awareness of, access to, and inclusion of multiple geographic contexts (Indigenous Global North and South), thereby illuminating the intersectionality and diversity that Indigenous scholars, practitioners, and community members bring to language and evaluation activities;

2. build awareness and appreciation of the collaborative and effective work of multiple Indigenous and non-Indigenous partners and stakeholders through culturally responsive evaluation and language projects;

3. provide a multidisciplinary evidence base to document how the use of tribal critical and Indigenous theories, methods, and practices lead to more effective policy, studies, and practices of evaluation leaders, scholars, and practitioners;

4. utilize evaluation case studies and activities to better support the implementation, governance and policy understandings, and evidence base regarding the 2008 UNDRIP; and

5. offer new global paradigms from diverse Indigenous perspectives and language/evaluation practices to inform the gaps in the literature base so that the broader global society can utilize more effective and responsive human rights, peace, and reconciliation efforts when working with Indigenous peoples and Tribal/First Nations governments, in the future.

Given these examples of EvalIndigenous activities, the next section concludes with key discussion points for the larger field of evaluation to consider. There are concrete ways to get involved right away. Some mid- to long-range thoughts for active and strategic participation with partners and allies of EvalIndigenous are provided. These short- and longer-term suggestions for professional practice, partnership building, developing policies, and systemic capacities are then shared.

\section{EVALINDIGENOUS: FUTURE CONSIDERATIONS FOR THE BROADER FIELD OF EVALUATION}

The VOPE survey indicated work that should be undertaken with VOPEs. In some cases, it may be to increase understanding of who Indigenous peoples are in their jurisdictions. This may be a complex and long process, given the systems, subsystems, and governance and practice by each Indigenous community or First/ Tribal Nation, but it is possible, as demonstrated by the work of EvalIndigenous and the published scholarship of the EvalIndigenous global work group members.

Next, there is work to be done to introduce VOPEs to Indigenous approaches to evaluation, building reciprocal and sustainable partnerships, and including appropriate cultural and legal protocols, policies, and processes. Using the VOPE 
survey data intentionally, in publications, initiatives, policy position papers, or for policy and leadership planning discussions, is an important step forward. We believe that continued use of this survey will help document whether Indigenous people and Nations are becoming members of VOPEs. Furthermore, the survey will indicate if VOPEs working with Indigenous peoples and communities are using guidelines in their work. It is also important that the work of the Indigenous Voices Project must be disseminated and used as a resource by VOPEs to cultivate better understanding and use of different evaluation approaches and methods. This will help to ensure that evaluators and evaluations are authentic and inclusive. Dissemination must occur through a variety of vehicles, such as presentations at conferences, webinars, person-to-person conversations, information pamphlets, and social media.

It will be an excellent start to get to know the existing data and testimonials of the Indigenous Voices Project participants. Utilizing the leadership and political motivation of VOPEs to continue gathering data would provide a deeper level of commitment to Indigenous inclusion in nation/state efforts. Having testimonials become part of the election process for leadership and key policy or evaluation task forces is critical to relationship building and effective evaluation leadership, policy, and practice.

A long-term goal of EvalIndigenous is also to promote Indigenous peoples' self-determination of their evaluation agenda. This may be a locally created agenda, within Indigenous populations belonging to a VOPE, or broadly as part of EvalIndigenous and EvalPartners' 2030 work. Alternatively, it may be developed by Indigenous organizations and/or Tribal/First Nations as they see fit, which may exist outside the confines of the evaluation professional groups. The work of the Indigenous Voices Project will provide evidence to funders that Western approaches to evaluation are inappropriate for Indigenous peoples living in Indigenous communities.

Using the UNDRIP articles within governance, evaluation standards, professional credentialing, and evaluation policy and planning (e.g., EvalSDG) is very important to supporting a longer-term reconciliation agenda. For example, direct inclusion of sovereign Tribal/First Nations (over 1,000 in North America) and Indigenous communities/organizations in the EvalSDG 2030 plan is warranted. It may also be possible to include UNDRIP as a crosswalk, capacity-building, and monitoring effort in all EvalSDG publications and activities regarding the 2030 agenda or other global initiatives. This would build the institutional and systemic capacities of the field of evaluation leaders, VOPEs, parliamentarians, academics, and practitioners. Resources must be appropriate to build capacity; this will take time. Inclusion in organizational strategic planning and operational practices support this intentional effort by VOPEs. Evaluation can build on the communities' spiritual cultural and social values, while supporting cultural resurgence. The focus of an Indigenous approach should not be individuals, competition, and independence (i.e., positivist and western or colonized approaches) but should be about relationships, interdependence, and the community/collective vision 
for what counts as success, evidence, and important to document and learn from. While many different methods can be utilized, it must be based on an Indigenous evaluation paradigm. As noted by Wilson (2008), Indigenous evaluation must leave behind the dominant paradigms and follow an Indigenous evaluation paradigm:

This paradigm is a circle made up of four interrelated entities: ontology, epistemology, axiology, and methodology. The entire circle is an Indigenous research paradigm. Its entities are inseparable and blend from one to the next. The whole paradigm is greater than the sum of its parts.... Relationality seems to sum up the whole Indigenous research paradigm ... an Indigenous research paradigm is relational and maintains relational accountability. (Wilson, 2008, p. 70)

In conclusion, a joint effort of Indigenous and non-Indigenous partners is needed to create positive and sustained change at the individual, policy, and systems levels (i.e., nation-to- nation means Tribal Nations being included and treated equally, as the UN does for any nation/state work) regarding Indigenous evaluation. Intentional relationship and systems development (i.e., international, national, and tribal governments) must occur in order for sustained change to be realized. To begin, UNDRIP must be included in all EvalPartners activities, and Tribal Nations must have representation as part of VOPEs, EvalPartners, and UN-related evaluation work. Evaluation culture and practices must move beyond typical networking to more non-Indigenous leadership (e.g., Global Parliamentarian Forum, VOPE leaders, EvalPartners), explicitly including Indigenous people and Tribal/ First Nations. The colonial Conquer Model (Newcomb, 2008) of doing our work must not continue to be replicated by ignorance or exclusion of EvalIndigenous and Indigenous people and governments. Failure to equally include Indigenous participation politically, culturally, and practically in evaluation policy and initiatives means that the same negative practices of the past are being reinforced and will continue. Together the field of evaluation can move forward and start a new era, using a reconciliation lens, working collaboratively and more effectively for a better future.

\section{NOTE}

1 The views expressed in this article reflect those of the authors and do not necessarily reflect those of EvalPartners or EvalIndigenous.

\section{REFERENCES}

Alfred, G. T. (2009). Colonialism and state dependency. International Journal of Indigenous Health, 5(2), 42-60.

American Museum of Natural History. (n.d.). Center for Biodiversity and Conservation. Retrieved from https://www.amnh.org/research/center-for-biodiversity-conservation

Barker, J. (Ed.). (2005). Sovereignty matters: Locations of contestation and possibility in Indigenous struggles for self-determination. Lincoln, NE: University of Nebraska Press. 
Bowman, N. (2018). Looking backward but moving forward: Honoring the sacred and asserting the sovereign in indigenous evaluation. American Journal of Evaluation, 39(4), 543-568. https://doi.org/10.1177/1098214018790412

Bowman, N. (2019). Nation to nation evaluation: Governance, tribal sovereignty, and systems thinking through culturally responsive Indigenous evaluations. Canadian Journal of Program Evaluation, 34(2), 343-356. https://doi.org/10.3138/cjpe.67977

Bowman, N. (in press). Nation-to-nation in evaluation: Towards an Indigenous evaluation model to frame systems and government evaluations. New Directions for Evaluation.

Bowman, N., \& Dodge-Francis, C. (2018). Culturally responsive Indigenous evaluation and tribal governments: Understanding the relationship. New Directions for Evaluation, 2018(159), 17-31. https://doi.org/10.1002/ev.20329

Bowman, N. R., Dodge-Francis, C., \& Tyndall, M. (2015). Culturally responsive Indigenous evaluation: A practical approach for evaluating Indigenous projects in tribal reservation contexts. In S. Hood, R. Hopson, \& H. Frierson (Eds.), Continuing the journey to reposition culture and cultural content in evaluation theory (pp. 335-360). Charlotte, NC: Information Age.

Brayboy, B. M. J. (2005). Toward a tribal critical race theory in education. Urban Review, 37(5), 425-446. https://doi.org/10.1007/s11256-005-0018-y

Bremner, L. K., \& Were, L. (2016). Revised EvalIndigenous concept paper. Retrieved from http://forum.ioce.net/forum/open-forums/evalindigenous

Chandna, K., Vine, M., Snelling, S., Harris, R., Smylie, J., \& Manson, H. (2019). Principles, approaches, and methods for evaluation in Indigenous contexts: A grey literature scoping review. Canadian Journal of Program Evaluation, 34(1). https://doi.org/10.3138/ cjpe.43050. Retrieved from https://evaluationcanada.ca/system/files/cjpe-entries/34-1pre001.pdf

Chilisa, B. (2012). Indigenous research methodologies. Thousand Oaks, CA: Sage Publications.

Cram, F., Tibbetts, K. A., \& LaFrance, J. (Eds.). (2018). Editors' notes: A stepping stone in Indigenous evaluation. New Directions for Evaluation, 2018(159), 7-16. https://doi. org/10.1002/ev.20327

Easby, A. (2016). Indigenous research methodologies: Final report. Global Thematic Review on Training in Community-Based Research. Retrieved from http://unescochair-cbrsr. org/pdf/resource/kp/UVic_IRM.pdf

Echo-Hawk, W. R. (2013). In the light of justice: The rise of human rights in Native America and the UN Declaration on the Rights of Indigenous Peoples. Golden, CO: Fulcrum.

EvalPartners. (n.d.). Home [YouTube Channel]. Retrieved from https://www.youtube.com/ user/EvalPartners/videos

EvalIndigenous. (2019a). EvalSDGs Pop-Up Note 7: EvalIndigenous Introduction. Retrieved from https://lookaside.fbsbx.com/file/Jan\%202019\%20Final\%20PUN_EvalIndigenous\% 20Introduction.pdf?token=AWxExMyoOY53vb14QwO9QAZYFtzXKzrVz2mCJpaIp7eTci0Jd2nEWWBLQ7Y34NAT-5U1hv2FE2nfL9wQctlzbJGeY3I4yVXxW RO_BH0hTAb1p1fhdoqWUqLEbagwCYIVsyMWfxm-1SPsGDG2eJxO8tHzqI7TyPItXXfm2SBfcs9TnwDdAE6J4JmYlZzBz6S8Mk3MgWVOpJcZ3GghJ94vwWK 
EvalIndigenous. (2019b). Indigenous evaluation - Anacona Yanakuna. YouTube. Retrieved from https://www.youtube.com/watch?v=of232hnUpFQ\&list=PLfaZaOrP5173_kyp0 9pMfaNkrSq4LQzYd\&index $=10$

EvalIndigenous. (2019c). Indigenous evaluation - Edwin Chinguad. YouTube. Retrieved from https://www.youtube.com/watch?v=QINQsi_qyU8\&list=PLfaZaOrP5173_ kyp09pMfaNkrSq4LQzYd\&index $=9$

Gaudry, A. J. P. (2011). Insurgent research. Wicazo Sa Review, 26(1), 113-136.

Goodwin, D., \& Bremner, L. (2018). EvalIndigenous VOPE survey report. Retrieved from https://www.evalpartners.org/evalindigenous/about

Kirkhart, K., LaFrance, J., \& Nichols, R. (2011). Improving Indian education through Indigenous evaluation. Annual American Educational Research Association Conference, New Orleans, LA.

Kovach, M. (2010). Indigenous methodologies: Characteristics, conversations, and contexts. Toronto, ON: University of Toronto Press.

Kukutai, T., \& Taylor, J. (Eds.). (2016). Indigenous data sovereignty: Toward an agenda. Acton, Australia: Australian National University Press.

LaFrance, J., \& Nichols, R. (2010). Reframing evaluation: Defining an Indigenous evaluation framework. Canadian Journal of Evaluation, 23, 13-31.

Mā te Rae - Māori Evaluation Association. (n.d.). Facebook page. Retrieved from: https:// www.facebook.com/MaTeRae/?eid=ARDGVlWmPOjPRrj8loPnZgt5BPV8cOiu2shJ yREPjL2Bm56GfTeN7Qv1-FR2BSkLDs6YAeDRzRCsqkHt

Mertens, D. M., Cram, F., \& Chilisa, B. (Eds.). (2013). Indigenous pathways into social: Voices of a new generation. Walnut Creek, CA: Left Coast Press.

National Congress of American Indians. (2006-2019). Tribal leader/scholar forum. Retrieved from http://www.ncai.org/policy-research-center/initiatives/tribal-leaderscholar-forum

Newcomb, S. T. (2008). Pagans in the promised land: Decoding the doctrine of Christian discovery. Golden, CO: Fulcrum.

Reinhardt, M. (2008). Trust doctrine. In D. L. Fixico (Ed.), Treaties with American Indians: An encyclopedia of rights, conflicts, and sovereignty (pp. 161-194). Santa Barbara, CA: ABC-CLIO.

Rowe, G., \& Kirkpatrick, C. (2018). Na-gah mo waabishkizi ojijaak bimise keetwaatino: Singing white crane flying north: Gathering a bundle for Indigenous evaluation. Winnipeg, MB: Canadian Centre for Policy Alternatives. Retrieved from https:// www.policyalternatives.ca/sites/default/files/uploads/publications/Manitoba\%20Office/2018/03/Gathering_A_Bundle_for_Indigenous_Evaluation.pdf

Shepherd, R., \& McCurry, P. (2018). Ottawa must talk to Canadians about nation-to-nation agenda. Policy Options. Institute for Research on Public Policy. Retrieved from https:// policyoptions.irpp.org/magazines/october-2018/ottawa-must-talk-to-canadiansabout-nation-to-nation-agenda/

Smith, L. T. (1999). Kaupapa Māori methodology: Our power to define ourselves. Unpublished paper presented to the School of Education, University of British Columbia, Vancouver, BC. 
Smith, L. T. (2012). Decolonizing methodologies: Research and indigenous peoples (2nd ed.). New York, NY: Zed Books.

UNESCO. (n.d.). Call for research papers within the context of the 2019 international years of indigenous languages. Retrieved from https://en.unesco.org/feedback/call-researchpapers-within-context-2019-international-year-indigenous-languages

United Nations. (2008). United Nations declaration on the rights of Indigenous people. Retrieved from http://www.un.org/esa/socdev/unpfii/documents/DRIPS_en.pdf

United Nations. (2017). Briefing note: Indigenous peoples' rights and the 2030 agenda. Retrieved from https://www.un.org/development/desa/indigenouspeoples/wp-content/ uploads/sites/19/2016/10/Briefing-Paper-on-Indigenous-Peoples-Rights-and-the2030-Agenda.pdf

United Nations. (n.d.). International year of indigenous languages 2019. Retrieved from https://en.iyil2019.org/

United Nations Permanent Forum on Indigenous Issues. (2019). UNPFII eighteenth session: 22 April-3 May 2019. Retrieved from https://www.un.org/development/desa/ indigenouspeoples/unpfii-sessions-2/18-2.html

United Nations Permanent Forum on Indigenous Issues. (n.d. a). Indigenous peoples, Indigenous voices: Fact sheet. Retrieved from https://www.un.org/esa/socdev/unpfii/ documents/5session_factsheet1.pdf

United Nations Permanent Forum on Indigenous Issues. (n.d. b). United Nations: Indigenous peoples. Retrieved from https://www.un.org/development/desa/indigenouspeoples/

Wehipeihana, N., Bailey, R., Davidson, E. J., \& McKegg, K. (2014). Evaluator competencies: The Aotearoa New Zealand experience. Canadian Journal of Program Evaluation, 28(3), 49-69.

Wilson, S. (2008). Research is ceremony: Indigenous research methods. Winnipeg, MB: Fernwood Publishing.

\section{AUTHOR INFORMATION}

Larry Bremner is a Métis man whose great-grandmother, Rose Boucher, was born in 1867 in St. Francis Xavier, Manitoba. She moved with her parents by ox team to St. Louis, Saskatchewan, in1882. In 1883, she married Moise Bremner. On November 19, 1883, Moise, his father William, and 28 other Métis signed a petition, protesting the 1883 Order in Council transferring the Métis lands at St. Louis to the Prince Albert Colonization Company; the petition was ignored by the Canadian government. During the 1885 Métis Resistance at Batoche, Moise was a member of Captain Baptiste Boucher's company, one of the 19 dizaines (groups of 10 people) led by Gabriel Dumont. After the resistance at Batoche, the family moved to the United States, returning to what is now Saskatchewan after the Canadian government granted amnesty. They homesteaded in Domremy, Saskatchewan, in 1905. Larry is a former Canadian Evaluation Society (CES) National President, CES Fellow, and award-winner. Larry established Proactive Information Services Inc. in 1984 to provide evaluation services to the not-for-profit and public sectors. He has worked across Canada in urban, rural, remote communities, Indigenous communities, as well as in Macedonia, Bosnia and Herzegovina, Czech Republic, Hungary, Mongolia, Slovakia, and Slovenia. Larry was the driving force behind the creation of EvalIndigenous and its first Chair. 
Nicole Bowman-Farrell is a traditionally practicing Mohican and Lunaape (Delaware) Indigenous community member. Her spirit name is Waapalaneexkweew (wahpah-lah-nay-wook; Flying Eagle Woman) Neeka ha (knee-kah-ha; she is) Newetkaski (Nah-wet-tah-kah-see; accompanied by) Newa (nay-wah; four) Opalanwuuk (oh-pahlun-knee-aye-wook; Eagles). For over two decades, Dr. Bowman has utilized traditional Indigenous knowledge and theories to inform her policy, evaluation, and professional practice at a project and nation-to-nation level between Tribal and non-Tribal Governments. Dr. Bowman received AEA's 2018 Robert Ingle Service Award (first Indigenous awardee) and works in services to build the capacities, knowledge, and skills of Indigenous and non-Indigenous stakeholders so that mutual and respectful relations result in more impactful and sustainable changes. She is a member of the Blue Marble Global Evaluators (2019) and has served as the American Evaluation Association's (AEA) Chair or Co-Chair for the Indigenous Peoples in Evaluation since 2015. Since 2016 she has been serving as AEA's representative for the International Working Group (IWG) and has an appointment on EvalIndigenous (sub-task force of EvalPartners). Dr. Bowman received her PhD (in 2015) from the University of Wisconsin-Madison, where she was on academic fellowship. Currently, she is employed by the Wisconsin Center for Educational Research at the University of Wisconsin-Madison as a culturally responsive evaluator. She is also the President/ Founder of Bowman Performance Consulting in Shawano, Wisconsin. 